\title{
DIMORPHISM IN CANDIDA ALBICANS. II. COMPARISON OF FINE STRUCTURE OF YEAST-LIKE AND FILAMENTOUS PHASE GROWTH
}

\author{
HIDEYO YAMAGUCHI, YAYOI KANDA, \\ AND MASAKO OSUMI* \\ Department of Microbiology, Faculty of Medicine, University of Tokyo \\ *Department of Biology, Japan Women's University, Tokyo
}

(Received November 17, 1973)

\begin{abstract}
The structure of both yeast-like $(\mathrm{Y})$ and filamentous $(\mathrm{F})$ phase growth of Candida albicans, morphogenesis of which was controlled by the different concentration of yeast extract added to the culture medium, was studied on electron micrographs of ultrathin sections. Parallel studies were also carried out by phase-contrast microscopy on external morphology of living cells. Compared to Y-phase cells which exhibited essentially the same cytology as that noted for C. albicans or Saccharomyces cerevisiae by many workers, F-phase cells were distinctly characterized by the extensive development of intracytoplasmic membrane systems (ICMS) and endoplasmic reticulum. Such ICMS appeared to originate from the cell membrane and, frequently, to form whorled structures composed of multiple layers of a unit membrane, resembling in appearance the corresponding structures reported for several filamentous fungi.
\end{abstract}

Vegetative development of Candida albicans may follow either one of two patterns of morphogenesis, known as mold-yeast dimorphism, in which the fungus may be in a filamentous $(\mathrm{F})$ form or a yeast-like form (Y). Various chemical and physical agents, such as cysteine $(1)$, serum $(2,3)$, phosphate $(4)$, and temperature of cultivation $(5,6)$ have been found to be responsible for morphological changes in C. albicans cells. Moreover, our preceding work (7) showed that Y-phase development in this fungus occurs when grown in the medium containing an optimal level of yeast extract, whereas its suboptimal level conducts to F-phase development. In association with this morphological transformation, significant changes in several macromolecular contents and the respiratory activity were produced.

Since the precise comparison in the ultrastructure of $C$. albicans cells in both $\mathrm{Y}$ - and F-phases has not been published as yet, we deemed it important to explore 
electron microscopical studies with each of the two phase growth. Working on C. albicans cultures, whose growth phase was controlled by the concentration of yeast extract in the culture medium, the present experiments were conducted to elucidate the morphological basis for dimorphic phase conversion of this pathogenic fungus.

\section{MATERIALS AND METHODS}

Organism and growth condition. The stock culture of C. albicans strain 6713 was maintained on Sabouraud's glucose-agar slants. Organisms in a Y-form were prepared for microscopy by transferring the 24-hr culture to the medium of the following composition in liter of distilled water: glucose $8.0 \mathrm{~g},\left(\mathrm{NH}_{4}\right)_{2} \mathrm{SO}_{4}$ $8.0 \mathrm{~g}, \mathrm{MgSO}_{4} \cdot 7 \mathrm{H}_{2} \mathrm{O} 0.6 \mathrm{~g}, \mathrm{KH}_{2} \mathrm{PO}_{4} 3.6 \mathrm{~g}, \mathrm{Na}_{2} \mathrm{HPO}_{4} \cdot 12 \mathrm{H}_{2} \mathrm{O} 1.2 \mathrm{~g}$, yeast extract (Difco) $10 \mathrm{~g}$ (pH 5.9). The medium having the same composition but with a reduced amount of yeast extract $(1.0 \mathrm{~g} / \mathrm{liter})$ was used to obtain a culture that predominantly consists of F-phase cells. Both cultures were grown at $30^{\circ}$ for $24 \mathrm{hr}$ on a reciprocal shaker and then prepared for microscopical analyses.

Electron microscopy. Cells were harvested by centrifugation and washed 3 times with distilled water. The washed cell pellet was fixed in $2.5 \%$ glutaraldehyde with $0.1 \mathrm{M}$ phosphate buffer $(\mathrm{pH} 7.2)$ for $2 \mathrm{hr}$ and then post-fixed in $1.5 \%$ potassium permanganate in the same buffer for $18 \mathrm{hr}$ at $4^{\circ}$. Thus fixed specimens were dehydrated by passage through an acetone series and embedded in methacrylate according to the method of LUFT (8). Ultrathin sections were made on an LKB ultramicrotome with glass knives. The sections were picked up on 200-mesh copper grids, prestained for $30 \mathrm{~min}$ with an $1.5 \%$ aqueous solution of uranyl acetate, post-stained with Reynold's lead citrate, and examined in JEOL electron microscopes, JEM-7A and JEM-100B.

Phase photomicroscopy. C. albicans cells, prepared as wet mounts, were observed under phase-contrast in a Nikon L optical microscope and photographs were with a Nikon AFM photographic attachment.

\section{RESULTS}

\section{Photomicroscopy}

C. albicans routinely multiplied by budding and yielded a Y-phase growth when an early stationary phase 24-hr culture on the Sabouraud's glucose-agar slant was placed in the fresh, yeast extract-optimal medium and grown aerobically for $24 \mathrm{hr}$. As illustrated in Fig. 1, such a culture consisted exclusively of ovoid cells. In contrast, when grown in a medium containing a suboptimal level of yeast extract, normal Y-form cells in the inoculum were almost completely replaced by F-form cells after $24 \mathrm{hr}$ of incubation (Fig. 2). The resulting filaments invariably appeared to outgrow from the parent Y-phase cells. The cylindrical 


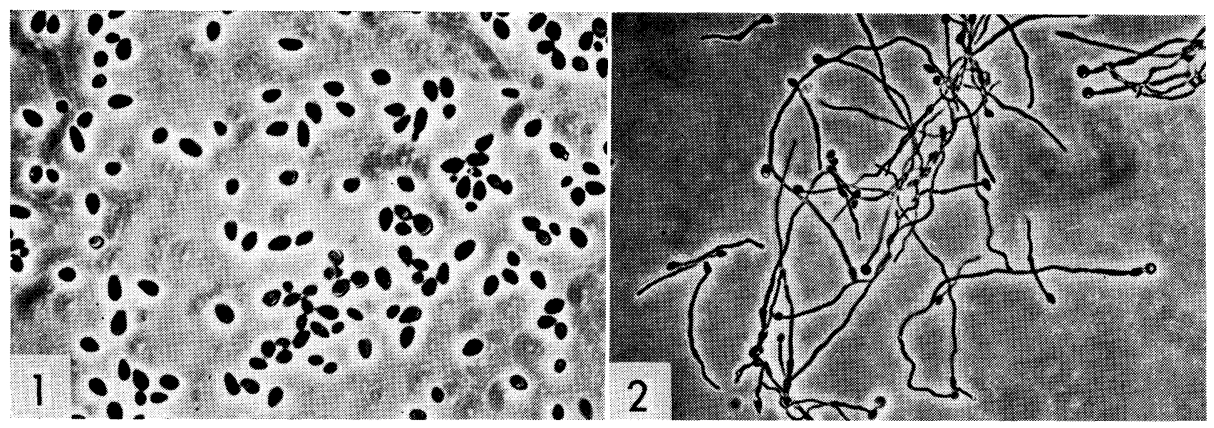

Figs. 1 and 2. Phase-contrast micrographs of $C$. albicans cells affected by the concentration of yeast extract in the growth medium.

Yeast-like (Y-phase) cells and filaments (F-phase cells) developing after 18-hr culture in yeast extract-optimal and -suboptimal media are respectively seen in Fig. 1 and Fig. $2 . \times 300$.

shape, longer length, and narrower width of F-phase cells clearly distinguished them from normally occurring bud or pseudomycelium. Most parent cells gave rise to a single outgrowth, and growing filaments were unbranched and were produced from any part of the surface of the parent Y-form cells. The filaments grew so long and were sneaky that they frequently became entangled with each other, resulting in the formation of large flocks. This $\mathrm{Y}$ to $\mathrm{F}$ phase conversion was assumed to result from continued growth without division.

\section{Electron microscopy}

$Y$-phase cells. Typical electron micrographs of ultrathin sections of Y-phase cells growing in yeast extract-optimal medium are illustrated in Figs. 3 and 4. An ovoid cell of roughly $5.5 \times 3.5 \mu$ was surrounded by the cell wall of about $140 \mathrm{~nm}$ thickness which displayed an electron-dense outer layer, a cell membrane-opposed inner layer, and a more transparent intermediate region as was described for Saccharomyces cerevisiae $(9,10)$. The cell membrane just beneath the cell wall, appearing as a unit membrane composed of an outer and inner electron-dense layers and a low-density middle space, was sinuous with occasional invaginations. These invaginations were about $30 \mathrm{~nm}$ wide and extended not more than about $50 \mathrm{~nm}$ into the cytoplasm. Within the cytoplasmic area were found usual organelles, such as nucleus, mitochondria, endoplasmic reticulum, and vacuole, the cytology of which closely resembled not only the electron micrographs of $C$. albicans published by other workers (11-16) but those of $S$. cerevisiae (17-19). Nuclei were slightly irregular in outline and frequently ovoid. They were enclosed by a double unit membrane, which at varying intervals was interrupted by 40 $70 \mathrm{~nm}$ pores, showing unobstructed continuity between the nucleus and the cytoplasm. Mitochondria were noted in sections mostly as elongated and circular profiles that were most often present near the periphery of the cytoplasm. As 
a rule, every cell had one large vacuole in the central area of the cytoplasm. In addition, the cytoplasmic interior contained small vesicles or short tubules in the peripheral region and, occasionally, long, smooth double-membrane elements. These membranous structures appeared to be identical in morphology with the endoplasmic reticulum of higher plant and animal cells. Y-phase cells of C. albicans were usually scarce of the endoplasmic reticulum or other intracytoplasmic membrane systems.

F-phase cells. Contrary to Y-phase morphology, filaments developing in yeast extract-suboptimal cultures were extremely elongated but narrow in width $(0.8-1.3 \mu)$ (Fig. 5). As consistently observed by a phase-contrast microscope, they outgrew from the parent Y-phase cells (Fig. 6). Septum was formed, as a rule, between new filamentous growth and the parent cell. In those cells which lacked septum, cytoplasmic continuity was maintained. The cell wall thickness measured from 70 to $90 \mathrm{~nm}$; it was thinner than that of Y-phase cells. Despite that, the comparable triple-layered architecture of the cell wall was detected (Figs. 7-9).

As compared with Y-phase cells, F-phase cells showed elongated and numerous profiles of mitochondria (Fig. 5); their long axis paralleled the long axis of the filamentous growth as in Neurospora crassa (20) but, in contrast to that, mitochondrial cristae lied parallel to the long axis of the rod-shaped organelles. Nuclei were also elongated and extended according to the filamentous cell shape, but any difference in fine structure of nuclear envelope or nucleoplasm was not observed. Vacuoles increased in size and number; sometimes, they occupied large spaces in the cytoplasm. The most striking differences in the cytology between $\mathrm{Y}$ - and

Figs. 3-9. Electron micrographs of ultrathin sections of Y- and F-phase cells.

The following symbols are used: $\mathrm{CW}$, cell wall; ER, endoplasmic reticulum; $\mathrm{I}$, invagination of cell membrane; $\mathrm{M}$, mitochondria; $\mathrm{N}$, nucleus; $\mathrm{NM}$, nuclear membrane; NP, nuclear pore; PM, cell membrane; VA, vacuole; W, whorled structure. The line in each figure indicates $1 \mu$.

Figs. 3 and 4. Y-phase cell. Note the cell wall, cell membrane, mitochondria, nuclei, and endoplasmic reticulum (Fig. 3), and, more finely, structural layers of cell wall, invaginations of cell membrane, and double unit membrane structure of endoplasmic reticulum and nuclear membranes with pores (Fig. 4).

Fig. 5. F-phase cell elongating without septal formation. Note the fine structure of intracytoplasmic organelles essentially similar to that of Y-phase cells.

Fig. 6. F-phase cell. Note septal formation (arrow) between a Y-form mother cell and an outgrowing filament.

Fig. 7. The septum of convexed form in an F-phase cell. Note three-layered cell wall construction and septum formation, the cytoplasmic area adjacent to which is rich in membranous structures like endoplasmic reticulum or more minute tubuli.

Fig. 8. F-phase cell. Intracytoplasmic whorled structures composed of concentric layers of membranes are prominent.

Fig. 9. Cross-section of an F-phase cell. Note well-developed endoplasmic reticulum, some of which run parallel to each other across the cytoplasmic area. 

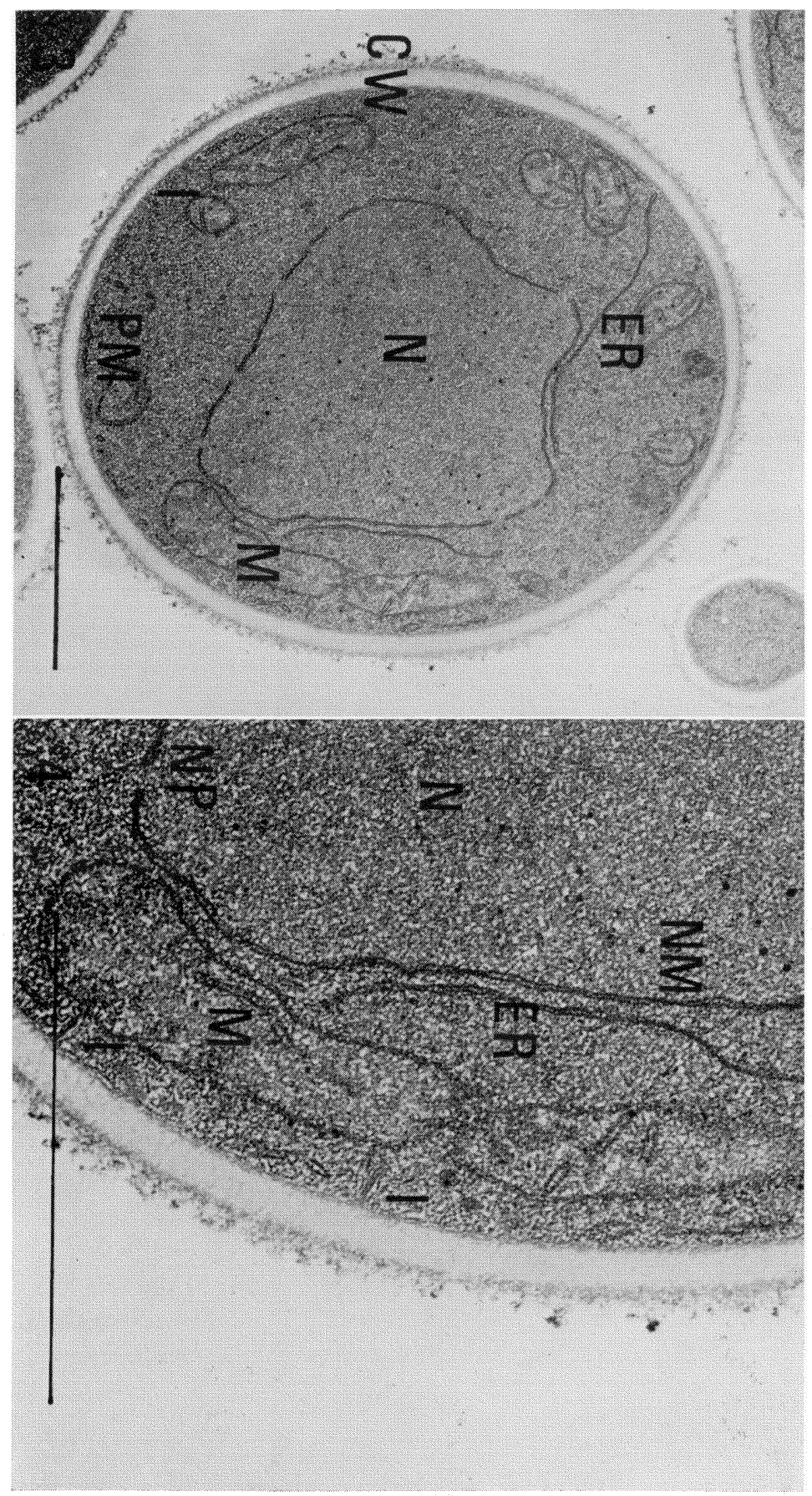


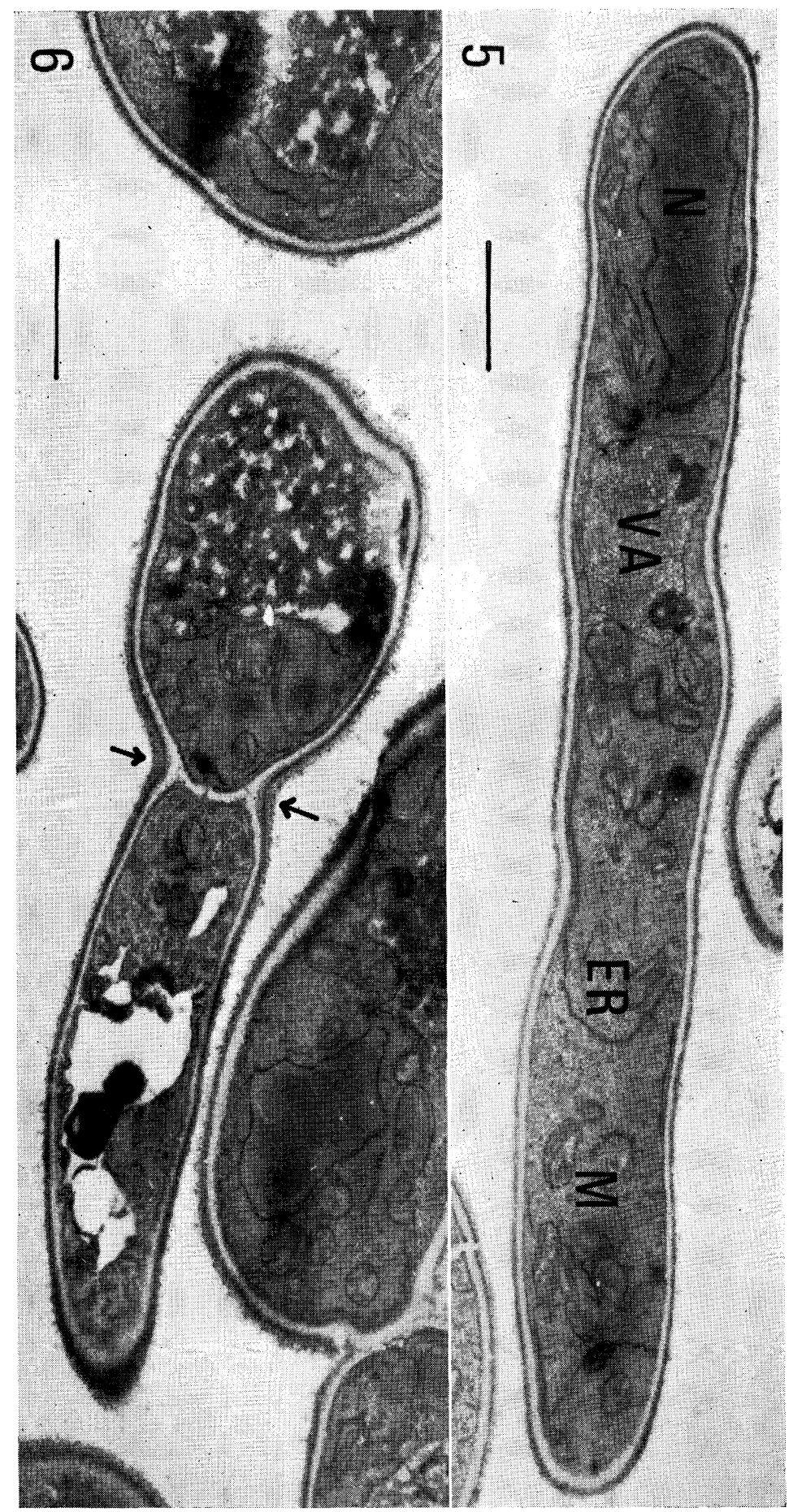




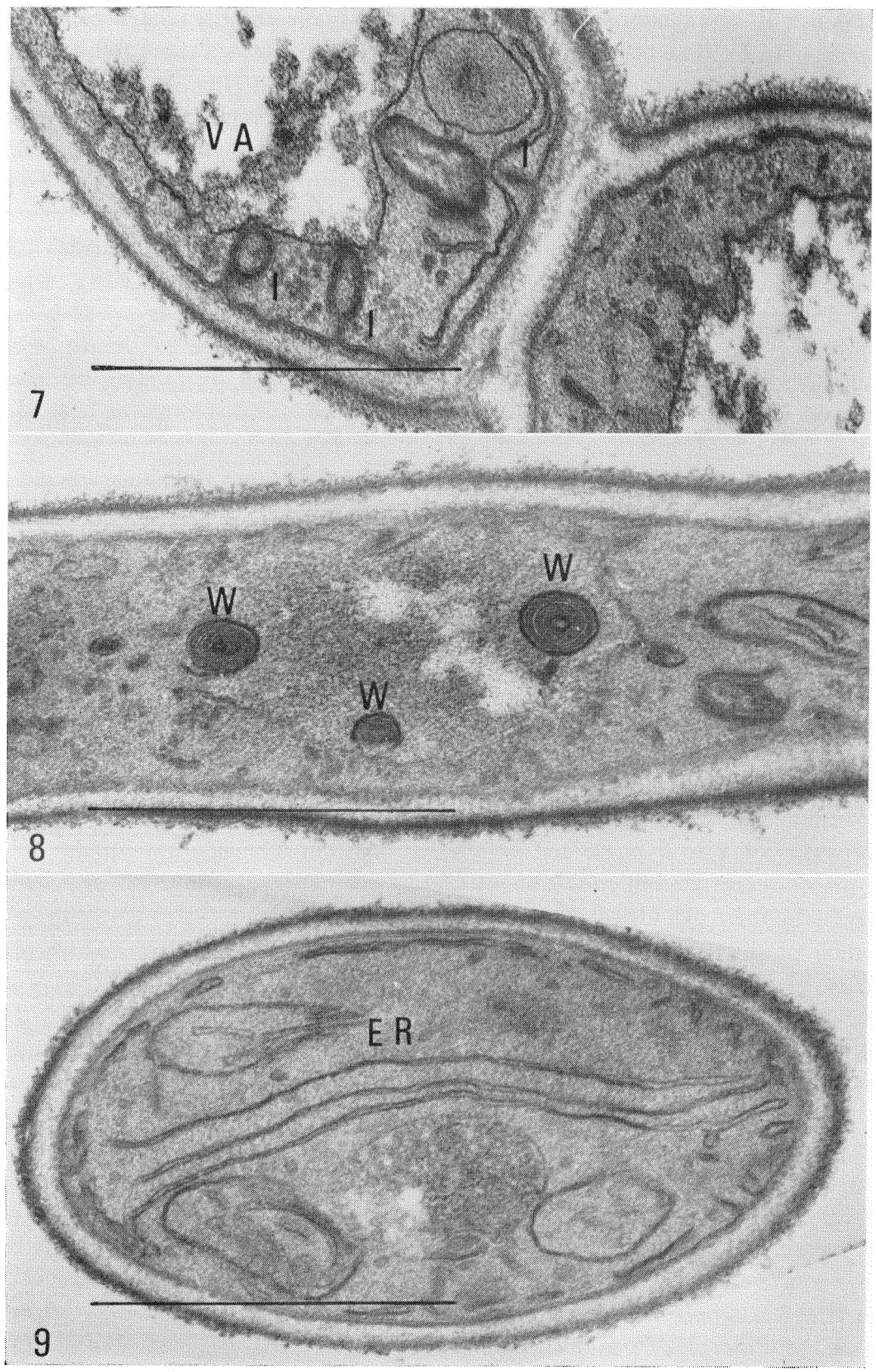


F-phase cells were demonstrated for the cell membrane and the related membrane systems. In F-phase cells, the cell membrane presented much more frequent and deeper invaginations than those observed in Y-phase cells (Fig. 7). Such invaginations were composed of two unit membranes that ran parallel throughout their entire length, and they frequently appeared as lamellae varying in length and curvature and protruding sharply into the cytoplasm. They usually remained as simple invaginations, but occasionally folded upon themselves to form concentric layers, presumably developing into more complex membrane systems. Extensive development of intracytoplasmic membrane systems (ICMS), which typically appeared as whorled structures composed of multiple layers of a unit membrane, was characteristic of F-phase cells (Fig. 8). Since continuity of the limit membrane of these whorled structures with the cell membrane was often observed, the infolding of the cell membrane may be interpreted as the beginning of the ICMS. In addition, the endoplasmic membranous structure, termed as the endoplasmic reticulum, developed better in F-phase cells than encountered in $\mathrm{Y}$-phase cells. The structure was particularly prominent in appearance in crosssections of F-phase cells (Fig. 9).

\section{DISCUSSION}

Mycelial phase cells of typical dimorphic fungi, e.g., Blastomyces dermatitidis, Paracoccidioides brasiliensis, and Histoplasma capsulatum, have been well known to develop by axial elongation of the Y-phase cell during phase conversion. In contrast, filamentous morphology of $C$. albicans usually outgrows from the parent Y-phase cell, which persists at the origin of filamentous growth even after the completion of $\mathrm{Y}$ to $\mathrm{F}$ phase conversion. C. albicans filaments developing under the present experimental condition are clearly distinguished from buds or pseudomycelia by their cylindrical growth with longer length and narrower width, and by their production from any part of the surface of the parent cell. These properties of external morphology are comparable with those of "germ-tubes" typically occurring in vivo $(21,22)$ or in vitro in the presence of serum $(3,23)$. Moreover, the fine structure of the filaments (F-phase cells) is found to resemble that of germ-tubes rather than of pseudomycelia in that they appear to elongate by apical growth and to form subsequent septa, representing true mycelia.

The most conspicuous differences between Y- and F-phase cells at the ultrastructural level seem to be in the intracytoplasmic constitution of membranous structures; F-phase cells revealed frequent occurrence of deep invaginations of the cell membrane, the extensive ICMS, and the endoplasmic reticulum, whereas either of these structures was scarcely or only poorly developed in Y-phase cells. The ICMS has been described in several human pathogenic and non-pathogenic molds and dimorphic fungi in the F-phase but not in yeasts or yeast-like fungi (20, 24-26). In C. albicans, the ICMS is shown to be confined to F-phase cells and 
to resemble the corresponding structure reported for above-cited mycelial fungi as well as bacterial mesosomes in following respects; (1) it originates from the cell membrane as a large invagination and (2) it subsequently expands into the cytoplasm to form a whorled structure consisting of multi-layered unit membrane. The main significance of the invagination of the cell membrane into the cell interior is that it possibly results in a substantial extension of the cytoplasmic surface area being in contact with the external medium, since the pores in the cell wall are probably large enough to allow free passage of all except large molecules. Therefore, the occurrence of the ICMS may enhance the exchange of materials between the cell and the environment. Such a possibility has been suggested by VAN ITERSON (27). In this connection, it should also be noted that the filamentous morphology is in favor of extension of cell surface as compared with Y-phase growth. Thus, it looks likely that both of these two, external and internal, anatomical characteristics for F-phase growth would provide increased opportunities for active transport of essential nutrients, such as those contained in yeast extract, between the external medium and interior of the organism. If this is the case, F-phase-specific morphology may develop to compensate for depleted addition of such nutrients to the medium. The correlation between the invagination of the cell membrane and cellular activities has been described in yeast spores (28) and in vegetative forms of $N$. crassa (20). There are publications which show close association of the ICMS with cell division and septal formation in certain species of bacteria $(29,30)$ and with ascospore cell wall formation in Penicillium vermiculatum (31). Appearance of the extensive ICMS is also found during yeastlike to mycelial phase conversion in some pathogenic dimorphic fungi other than C. albicans $(32,33)$. In a similar way, frequent occurrence of the ICMS in Fphase cells of $C$. albicans might be correlated with the formation of cell walls or septa, leading to the development of true mycelia.

Concerning the endoplasmic reticulum, it is far from any definite conclusions for the moment as to its function or role in the morphogenetic processes of $C$. albicans cells. Because such an obvious connection between the membrane of the endoplasmic reticulum and the cell membrane as that described with mammalian cells (34) cannot be seen here, it still remains a question whether the endoplasmic membranous component of $C$. albicans, termed as the endoplasmic reticulum on the basis of morphological analogy, has a similar function as that of the corresponding organelle of mammalian cells, "the import, export, and intracellular circulation of various substances" according to PALADE (34). HAwKER (35) suggested that the endoplasmic reticulum in fungal cells may generally become numerous in areas of increased activity, such as reproductive organs, e.g., the young zygospores of Phycomyces or the haustoria of certain parasitic fungi. It would, therefore, seem that extensive development of the endoplasmic membranous system in F-phase cells of $C$. albicans reflects an accelerated state of their functional activity. 
The preceding paper of this series of study has shown that certain cellular metabolisms involved in macromolecular synthesis and energy production are profoundly altered in association with Y- to F-phase morphological transformation (7). Experiments are currently in progress to examine whether such phasedependent alterations of metabolic patterns are related to cytological reorganization, particularly with respect to development of the ICMS and the endoplasmic reticulum, as a cause or a consequence.

We thank Dr. K. Iwata for his helpful advice during the course of this work.

\section{REFERENCES}

1) W. J. Nickerson and N. J. W. VAN RiJ, Biochim. Biophys. Acta, 3, 461 (1949).

2) J. W. Landau, N. Dabrowa, V. D. Newcomer, and J. R. Rose, J. Invest. Dermatol., 43, 473 (1964).

3) D. W. R. MACKensie, J. Clin. Pathol., 15, 563 (1962).

4) A. Widra, Mycopathol. Mycol. Appl., 23, 197 (1964).

5) N. Dabrowa, D. H. Howard, J. W. Landau, and Y. Shechter, Sabouraudia, 8, 163 (1970).

6) F. W. Chattaway and M. R. Holmes, J. Gen. Microbiol., 51, 367 (1968).

7) H. Yamaguchi, J. Gen. Appl. Microbiol., 18, 87 (1974).

8) J. H. Luft, J. Biophys. Biochem. Cytol., 9, 409 (1961).

9) E. Vitols, R. J. North, and A. W. Linnane, J. Biophys. Biochem. Cytol., 9, 689 (1961).

10) H. MARQuARDT, Z. Naturforsch., 17B, 689 (1962).

11) A. TAKagi and A. Nagata, Japan. J. Microbiol., 6, 95 (1962).

12) K. Iwata and T. Hirata, Japan. J. Bacteriol., 18, 393 (1963), in Japanese.

13) A. BAKerspigel, J. Bacteriol., 87, 228 (1964).

14) K. Iwata and T. Hirata, Japan. J. Bacteriol., 21, 533 (1966), in Japanese.

15) T. Akisada, J. Tokunaga, and M. Kobayashi, Japan. J. Bacteriol., 21, 1 (1966), in Japanese.

16) J. Tokunaga, M. Tokunaga, T. Egashira, and K. Harada, Japan. J. Bacteriol., 24, 661 (1969), in Japanese.

17) H. D. Agar and H. C. Douglas, J. Bacteriol., 73, 365 (1957).

18) T. Hashimoto, S. F. Conti, and H. B. NaYlor, J. Bacteriol., 76, 406 (1958).

19) T. Hirano and C. C. Lindegren, J. Ultrastruct. Res., 5, 321 (1961).

20) A. J. Schatkin and E. L. Tatum, J. Biophys. Biochem. Cytol., 6, 423 (1959).

21) W. BLYTH, Mycopathologia, 10, 91 (1958).

22) D. W. R. MACKensie, Sabouraudia, 3, 225 (1964).

23) C. L. Tachdjian, J. J. Burchall, and P. J. Kozinn, J. Dis. Child., 99, 212 (1960).

24) B. Blondel and G. Turian, J. Biophys. Biochem. Cytol., 7, 127 (1960).

25) G. A. Edwards and M. R. Edwards, Am. J. Botany, 47, 622 (1960).

26) L. M. Carbonell, J. Bacteriol., 96, 533 (1968).

27) W. Van Iterson, J. Biophys. Biochem. Cytol., 9, 183 (1961).

28) T. HASHIMOTO, S. F. ConTI, and H. B. NAYLOR, J. Bacteriol., 76, 406 (1958).

29) T. Imaeda and M. Ogura, J. Bacteriol., 85, 150 (1963).

30) D. J. Ellar, D. G. Lundgren, and R. A. Slepecky, J. Bacteriol., 94, 1189 (1967).

31) R. Wilsenach and M. Kessel, J. Gen. Microbiol., 40, 401 (1965).

32) L. M. Carbonell and J. Rodriguez, J. Bacteriol., 96, 533 (1968).

33) R. G. Garrison, J. W. Lane, and M. F. Field, J. Bacteriol., 101, 628 (1970).

34) G. E. Palade, J. Biophys. Biochem. Cytol., Suppl. 2, 85 (1956).

35) L. E. HAWker, Biol. Rev., 40, 52 (1965). 